\title{
CRISIS RURAL Y MIGRACIONES EN CHIAPAS
}

\author{
DANIEL VILLAFUERTE SOLÍS* \\ MARÍA DEL CARMEN GARCÍA AGUILAR*
}

Resumen. La migración de chiapanecos a Estados Unidos está cobrando proporciones que rebasan los ámbitos comunitario y local para convertirse en un fenómeno estatal, lo cual redunda en el surgimiento de nuevos patrones culturales y la reestructuración de la vida comunitaria. En este artículo realizamos un primer acercamiento al fenómeno considerando los cambios en la estructura socioeconómica de la sociedad rural chiapaneca. Nuestro argumento es que el crecimiento de la migración deviene de la crisis rural que se gesta en 1988, se profundiza en 1989 con la caída del nivel internacional de los precios del café y se agrava más recientemente con el huracán Mitch y el levantamiento armado del ezLn. Paradójicamente, en el último lustro la migración internacional se ha convertido en un factor cada vez más importante para paliar la grave crisis en que se encuentran miles de familias campesinas chiapanecas.

Palabras ClaVe. Crisis rural, estructura agraria, migrantes, remesas, Chiapas.

ABSTRACT. The migration from Chiapas to the United States is reaching such proportions that it goes beyond the community and local levels, to become a state phenomenon. This results in the emergence of new cultural patterns and the restructuring of community life. In this article we attempt a first approach at this phenomenon taking into account the changes in the socioeconomic structure of Chiapas' rural society. We argue that the growth of migration results from the rural crisis generated in 1988, deepened in 1989 with the collapse of international coffee prices, and aggravated more recently by hurricane Mitch and the EzLN's armed uprising. Paradoxically, in the last five years, international migration has become an increasingly important factor to palliate the grave crisis in which thousands of Chiapas families live.

KEYWORDS. Rural crisis, agrarian structure, emigrants, remittances, Chiapas.

"Profesores investigadores del Centro de Estudios Superiores de México y Centroamérica de la Universidad de Ciencias y Artes de Chiapas. Correos electrónicos: ‘gasoda_2000@yahoo.com.mx〉y ‘mcgarcia2005@yahoo.com.mx». 


\section{INTRODUCCIÓN}

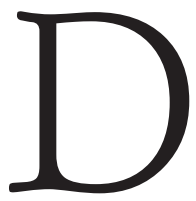

e acuerdo con el Consejo Nacional de Población (CONAPO), hasta el año 2000 Chiapas no tenía un lugar importante en el mapa de las migraciones a Estados Unidos. Según este organismo, la entidad ocupaba un grado de intensidad migratoria muy bajo (-1.24572) frente a entidades como Zacatecas, cuyo grado se clasificaba como muy alto (2.58352). Sin embargo, en 2004, Chiapas se colocó por arriba de Zacatecas en materia de captación de remesas familiares, lo que significa que, en sólo cuatro años, el estatus migratorio del estado habría cambiado significativamente.

En Los ausentes, un libro clásico dentro de los estudios del fenómeno migratorio, Massey, Alarcón, Durand y González formulan un punto de partida para el estudio de las migraciones:

[...] la migración se origina históricamente en los cambios de la estructura socioeconómica de las sociedades de origen y destino; que una vez implementadas, las redes de relaciones sociales sirven para apoyar e incrementar el flujo migratorio; que al aumentar la accesibilidad a la migración internacional, las familias la hacen parte de sus estrategias de sobrevivencia y la utilizan sobre todo cuando están en una etapa del ciclo de vida familiar en que es mayor el número de dependientes; que las motivaciones individuales, las estrategias familiares y las estructuras de la comunidad son afectadas por la migración de tal manera que hacen más plausible la emigración posterior; que aun entre los emigrantes temporales hay un proceso inevitable de establecimiento en el extranjero, y que entre los emigrantes establecidos existe un proceso de migración de retorno (Massey, Alarcón, Durand y González, 1991: 15).

A partir de esta idea, nos proponemos tener un primer acercamiento del fenómeno migratorio en Chiapas, considerando los cambios en la estructura socioeconómica en la sociedad rural chiapaneca pero, sobre todo, de la crisis de la producción y de los productores, crisis que comienza a partir de 1988 y se profundiza en 1994, con el levantamiento armado del Ejército Zapatista de Liberación Nacional (EzLN). No hay que olvidar que Chiapas es un estado predominantemente rural, pues, de acuerdo a los datos censales de 2000, 71.4\% de su población vivía en el campo: $54.4 \%$ en localidades menores de 2,500 habitantes y $17 \%$ en menores de 15 mil habitantes. Además, en el mismo año, 47.3\% de la Población Económicamente Activa (PEA) se encontraba vinculada a las actividades agropecuarias, mientras que, en todo el país, la proporción fue de sólo 15.8\%.

También se considera, como un detonante de la migración, los devastadores efectos del huracán Mitch en las regiones de la Costa y Sierra Madre de Chiapas, historia que se repite con el reciente huracán Stan cuyos resultados, en términos 
de destrucción, fueron tres o cuatro veces mayores. Consideramos que Stan inaugurará un nuevo ciclo en las migraciones internacionales de chiapanecos.

No nos detendremos en el análisis de las redes sociales, que es un aspecto clave para comprender el crecimiento de los flujos migratorios, debido a que el avance de nuestras investigaciones todavía no arroja mucha luz en este tema. Además, la migración internacional es muy reciente, por lo cual consideramos que es muy pronto para hablar de la formación de «clubes» de chiapanecos en Estados Unidos o Canadá. Hay, sin embargo, pequeñas redes familiares o grupales pero, sobre todo, un sistema de «agencias de viajes» que han venido creciendo en los últimos años, las cuales cumplen un papel fundamental para el transporte de los migrantes chiapanecos a distintos puntos de la frontera con Estados Unidos.

Si bien enfatizaremos en la parte socioeconómica, no asumiremos el enfoque de la economía neoclásica, que ha sido uno de los sustentados por una parte de las explicaciones sobre el fenómeno migratorio. La tesis central, de esta perspectiva analítica, descansa en las asimetrías salariales entre regiones. Durand y Massey (2003: 14), sintetizan el planteamiento neoclásico en los siguientes términos: «[...] Un país con gran reserva laboral respecto al capital se caracteriza por un bajo salario; mientras que un país con una limitada reserva laboral respecto al capital se caracteriza por un salario alto. Los diferenciales salariales resultantes hacen que los trabajadores de los países con salarios bajos o con exceso de oferta laboral, se muevan hacia los países con salarios altos o con escasez de oferta laboral». Este planteamiento, si bien tiene sentido en general, en el contexto de Chiapas, el migrante se encuentra frente a la disyuntiva de permanecer desempleado o de emigrar a Estados Unidos, y esta última posibilidad permite obtener mayor remuneración. La elección racional que plantea la teoría neoclásica sólo se aplica de manera limitada y en contextos específicos; tal es el caso de los trabajadores agrícolas temporales que van a Canadá por ocho meses, que pueden, en cierto momento, optar por un empleador en Ontario o en Columbia Britanica, dependiendo del salario y otras prestaciones que ofrezca.

\section{NATURALEZA DE LA CRISIS RURAL}

La crisis rural que vive Chiapas, desde finales de la década de los ochenta, es profunda y de carácter estructural. El modelo de agricultura de plantaciones y de ganadería extensiva tocó fondo con la apertura comercial y la desregulación económica, misma que eliminó subsidios y diversos apoyos a la producción y comercialización. Como parte de las condiciones para la entrada en vigor del Tratado de Libre Comercio de América del Norte (TLCAN), se produjo un cambio sustancial en la política agraria y agropecuaria que generó diversos impactos en la población: por un lado, la cancelación del reparto agrario derivó en descontentos y tomas de tierras en toda la geografía chiapaneca, cuya mayor intensidad se observó durante 
el periodo 1994-1997. ${ }^{1}$ Por otro lado, la reducción de los subsidios generalizados en el campo y el cambio de subsidios indirectos a directos, sobre todo en materia de granos básicos, llevó a una recomposición de las áreas productivas maiceras, provocando una disminución progresiva en los rendimientos por unidad de superficie.

Por otra parte, el levantamiento armado del EzLn generó una serie de conflictos entre campesinos y propietarios rurales que impactó negativamente en las inversiones, tanto en la agricultura como en la ganadería, y provocó el desplazamiento de importantes grupos de población campesina. Aunado a lo anterior, el entorno macroeconómico generado por la macro devaluación del peso mexicano, a finales de 1994, originó que la economía chiapaneca, particularmente el sector primario, registrara un fuerte retroceso. Además, los precios agrícolas internacionales de los principales productos de exportación, particularmente el café, se combinaron con el ambiente desfavorable descrito anteriormente y provocaron la ruina de miles de productores. ${ }^{2}$

Como se puede observar en el cuadro uno, entre 1993 y 2003, el crecimiento del Pib en el país registró una tendencia decreciente. Primero se percibe un incremento moderado hasta el año 2000, sólo interrumpido por la crisis de 1995 y una leve baja en el año de 1999; luego se observa, a partir del año 2001, una tendencia decreciente que comienza con una tasa negativa en ese año. En el caso de Chiapas, con excepción de la caída del año 1995, el crecimiento de la economía se mantuvo en un promedio bajo y sólo en dos años (1997 y 1998) se registran incrementos superiores al $4.5 \%$.

Como un reflejo de la actividad económica global, el PIB del sector primario observa una tendencia de bajo crecimiento en el país, con un fuerte incremento en 2001 y una tasa negativa en 2002. En Chiapas, contrario a lo que ocurre en el ámbito nacional, se registra una brutal caída del PIB en 1994, como resultado del entorno macroeconómico y del conflicto armado y, sólo cuatro años más tarde, se logra recuperar la cifra que se había registrado en 1993. Inexplicablemente - sobre todo porque contrasta notablemente con la caída de los precios internacionales del café-, la tendencia se rompe en los años 1999 y 2000, al registrar crecimientos superiores a 13\% y 4\% respectivamente. Sin embargo, en 2001 se registran números negativos $y$, en los siguientes años, se mantienen con bajas tasas de crecimiento.

Si analizamos de otra manera las cifras de la riqueza generada en Chiapas y ponemos atención al PIB per cápita, nos daremos cuenta que el crecimiento en este indicador es francamente crítico (cuadro dos). De esta manera encontramos

\footnotetext{
${ }^{1}$ Véase Villafuerte, Daniel et al., 2002, La tierra en Chiapas. Viejos problemas nuevos, México, Fondo de Cultura Económica, 2002.

${ }^{2}$ Las estadísticas de la SAGARPA reportan la existencia de 107,779 productores y 240,800 hectáreas cultivadas de café.
} 
que, durante el periodo 2000-2003, el incremento fue sólo de 1.7\%, dato que nos revela la enorme disparidad entre el crecimiento del PIB y de la población, lo que se traduce en bajo crecimiento del empleo y permanencia en las condiciones estructurales de pobreza. La situación actual que presenta Chiapas no es sustancialmente mejor a la que había en 1993, un año antes del levantamiento zapatista: en ese año, el PiB per cápita fue de 6,065 pesos y, diez años después —en 2003-, alcanzó los 6,280 pesos, es decir, apenas un 3.5\% superior a lo obtenido una década anterior.

CUADRO 1

Producto interno bruto total y sector primario nacional y de Chiapas (miles de pesos a precios de 1993 y tasa media anual de crecimiento)

\begin{tabular}{|c|c|c|c|c|c|c|c|c|}
\hline AÑO & $\begin{array}{c}\text { TOTAL } \\
\text { NACIONAL }\end{array}$ & TMAC & $\begin{array}{c}\text { TOTAL } \\
\text { CHIAPAS }\end{array}$ & TMAC & $\begin{array}{c}\text { PRIMARIO } \\
\text { NACIONAL }\end{array}$ & TMAC & $\begin{array}{c}\text { PRIMARIO } \\
\text { CHIAPAS }\end{array}$ & TMAC \\
\hline 1993 & $1^{\prime} 155,132,189$ & - & $20,644,398$ & - & $72,702,941$ & - & $3,276,049$ & - \\
\hline 1994 & $1^{\prime} 206,135,039$ & 4.31 & $21,480,509$ & 4.00 & $72,833,904$ & 0.18 & $3,098,123$ & -5.58 \\
\hline 1995 & $1^{\prime} 131,752,762$ & -6.36 & $21,423,329$ & -0.26 & $74,168,209$ & 1.81 & $3,178,923$ & 2.57 \\
\hline 1996 & $1^{\prime} 190,075,547$ & 5.02 & $21,641,397$ & 1.01 & $76,983,581$ & 3.72 & $3,233,520$ & 1.70 \\
\hline 1997 & $1^{\prime} 270,744,065$ & 5.55 & $22,643,158$ & 4.52 & $77,105,776$ & 0.15 & $3,283,430$ & 1.53 \\
\hline 1998 & $1^{\prime} 334,586,475$ & 4.90 & $23,711,975$ & 4.61 & $79,438,586$ & 2.98 & $3,301,600$ & 0.55 \\
\hline 1999 & $1^{\prime} 384,674,491$ & 3.68 & $24,322,080$ & 2.54 & $80,627,331$ & 1.48 & $3,769,173$ & 13.22 \\
\hline 2000 & $1^{\prime} 475,927,095$ & 6.37 & $25,296,965$ & 3.93 & $80,934,684$ & 0.38 & $3,938,463$ & 4.39 \\
\hline 2001 & $1^{\prime} 475,438,954$ & -0.03 & $25,657,678$ & 1.41 & $85,742,277$ & 5.76 & $3,864,214$ & -2.05 \\
\hline 2002 & $1^{\prime} 486,792,334$ & 0.75 & $26,438,496$ & 2.99 & $84,932,998$ & -0.94 & $3,962,027$ & 2.79 \\
\hline 2003 & $1^{\prime} 508,240,009$ & 1.43 & $26,978,080$ & 2.02 & $88,386,535$ & 3.98 & $4,076,000$ & 2.83 \\
\hline
\end{tabular}

Fuente: INEGI, Sistema de Cuentas Nacionales de México

Las cifras del PIB, no obstante las dudas razonables para algunos años, son reveladoras del escenario tendencial en el que se mueve la producción y los productores. La cambiante situación de los precios de los principales productos, en los mercados nacional e internacional, y la vulnerabilidad de la producción, debido a la falta de una política agropecuaria consistente, han generado un ambiente en el cual el campesino o pequeño productor, incluso mediano, ha tenido que abandonar el campo para emprender nuevas actividades o emigrar a los Estados Unidos de Norteamérica. Como veremos enseguida, la situación del campo, vista por otros indicadores agrarios y de producción, proporciona una idea más precisa de la situación y contrasta, notablemente, con el manejo de las cifras de crecimiento que muestran fuentes gubernamentales. 
CUADRO 2

Producto Interno Bruto total y per cápita en Chiapas

(a precios constantes de 1993)

\begin{tabular}{|c|c|c|c|}
\hline \multirow{2}{*}{ AÑO } & $\begin{array}{c}\text { PIB TOTAL } \\
\text { (MILES DE PESOS) }\end{array}$ & $\begin{array}{c}\text { POBLACIÓN } \\
\text { (MILES DE HABITANTES) }\end{array}$ & $\begin{array}{c}\text { PIB PER CÁPITA } \\
\text { (PESOS) }\end{array}$ \\
\hline 2000 & $25,296,965$ & $4,097,136$ & $6,174.30$ \\
\hline 2001 & $25,657,678$ & $4,165,798$ & $6,159.12$ \\
\hline 2002 & $26,438,496$ & $4,231,031$ & $6,248.71$ \\
\hline 2003 & $26,978,080$ & $4,295,692$ & $6,280.26$ \\
\hline
\end{tabular}

Fuente: INEGI, Sistema de Cuentas Nacionales de México. Los datos de población son estimaciones realizadas por el gobierno del estado de Chiapas, publicadas en el Tercer Informe de Gobierno (anexo estadístico).

\section{El nuevo mapa agrario}

Luego de más de treinta años de lucha sistemática, los campesinos chiapanecos lograron el propósito de obtener la tierra. El último tramo para completar el largo proceso de apropiación de la tierra ocurrió durante el periodo 1994-1997, los cuatro años de mayor efervescencia del movimiento zapatista. Sin embargo, el costo social y económico de una reforma agraria tardía ha sido demasiado alto. Hoy, la mayor parte de la superficie agrícola y forestal está en manos de los campesinos (cuadro tres), pero tener la tierra no ha sido suficiente para garantizar la reproducción biológica y social del campesinado; el contexto ha cambiado radicalmente y las reglas ya no las impone el Estado, sino el mercado. Ahora éste se encarga de determinar la política gubernamental, no sólo en materia agraria sino, también, en lo que respecta al fomento a la producción.

El movimiento zapatista generó las condiciones que permitieron, a los campesinos y sus organizaciones, tener acceso a una superficie de aproximadamente 245,000 hectáreas, mismas que estaban en manos privadas. La coyuntura política no obligó al gobierno federal a cambiar la Ley Agraria para continuar con el reparto agrario, ${ }^{3}$ pero encontró la fórmula para adjudicar, a los campesinos, una buena parte de la tierra que demandaban, la cual estaba en torno a las 500 mil hectáreas. El viejo método de compras de tierras, que ya se había ensayado en el periodo

\footnotetext{
${ }^{3}$ No está de más señalar que las reformas al artículo 27 Constitucional en materia agraria, aprobadas en 1992, llevaron a cancelar el proceso de reparto agrario.
} 
del gobierno del general Absalón Castellanos (1982-1988), ${ }^{4}$ para solucionar conflictos en la zona norte y en el valle de Venustiano Carranza, se desempolvó y se institucionalizó con miras a establecer un complicado mecanismo de negociación con las organizaciones campesinas. Finalmente, los campesinos ganaron, pero el triunfo sirvió de poco para vigorizar su economía y alcanzar un mejor nivel de vida: al comenzar 1998, el mercado comenzó, una vez más, a castigar a los productores de café, al tiempo que las reglas del TLCAN no permitieron que el Estado subsidiara a los productores más allá de los términos pactados, que se concretan en los dos programas más importantes de apoyo a la producción agropecuaria: la Alianza para el Campo y los subsidios directos al campo (PROCAMPO) para el apoyo a los productores de maíz.

El año 2000 marca el cierre de un ciclo de lucha agraria, que termina, precisamente, con el proceso de ejidalización de las aproximadamente 245 mil hectáreas, producto de las compras de tierras efectuadas al calor del levantamiento armado de 1994. Sin embargo, hasta marzo del año 2000 se reconocía la existencia de 14,047 conflictos agrarios; un año después, el gobernador Pablo Salazar admitió, por primera vez, que el EZLN mantenía 275 predios invadidos en los municipios de Ocosingo, Las Margaritas y Altamirano; además indicó que 669 grupos y organizaciones, distintas al EzLn, habían solicitado la compra de $71 \mathrm{mil}$ hectáreas, que corresponden a 276 predios, de los cuales, 22\% ya se encontraban invadidos. Asimismo, aceptó que «diariamente llegan a la Secretaría de Desarrollo Rural nuevas solicitudes de tierra». ${ }^{5}$

A pesar de los cambios en la estructura y en el régimen de tenencia de la tierra, todavía se registran contradicciones propias de una sociedad atrasada. Aunque la lucha por la tierra ya no tiene el mismo significado que hace treinta años, los conflictos persisten, tan sólo en el periodo 2001-2003 se registraron 617 disputas agrarias, 271 de éstas (43.9\%) están referidas a invasiones de tierras; 122 (19.8\%) a regularización de tierras y $72(11.7 \%)$ a problemas de límites. ${ }^{6}$

Además de la persistencia del problema agrario, las políticas agrícolas no han contribuido a mejorar las condiciones de vida de la inmensa mayoría de campesinos y productores; por el contrario, se observa una pérdida acumulada de empleo y una tendencia a la disminución de la productividad, lo que tiene efectos en los ingresos y el consumo de la población rural. El sector agropecuario y forestal, que hasta la década de 1970 constituía el soporte de miles de familias campesinas,

\footnotetext{
${ }^{4}$ El gobernador Absalón Castellanos instituyó el Programa de Regularización Agraria (PRA) con el propósito de dar respuesta a las demandas de tierra y contener el descontento campesino; sin embargo, sus alcances fueron muy limitados ya que al iniciar el periodo gubernamental de Castellanos, en 1988, se tenía una estadística de 203 predios invadidos y al finalizar, en 1988, se contabilizaron 428 invasiones de tierra (véase, Reyes, 1994; Villafuerte et al., 2002).

${ }^{5}$ La Jornada, 15 de abril de 2001.

${ }^{6}$ Véase Tercer Informe de Gobierno. A la mitad de un buen camino, anexo estadístico, 2003.
} 
está en un proceso de crisis estructural. La contribución de este sector en el PIB, en el año 2003, fue de sólo 15.1\%, mientras que, en 1970, era de 30.8\%; a todo lo anterior hay que agregar la incapacidad del sector para mantener los empleos y generar nuevos para la Población Económicamente Activa (PEA) que crece cada año. La pérdida de expectativas de empleos, para miles de jóvenes hijos de campesinos, está llevando a un proceso de envejecimiento de fuerza laboral en el campo y a un proceso de feminización de algunos procesos agrícolas, como el café, situación que tenderá a generalizarse en los próximos cinco años como consecuencia del incremento de las migraciones.

Otro problema que enfrenta el campo chiapaneco es el minifundio; en buena medida, la cuestión del fraccionamiento de la tierra radica en el crecimiento de la población, que en las últimas tres décadas pasó de, aproximadamente, un millón 570 mil a casi cuatro millones —3 millones 920 mil 515 habitantes, según el Censo de Población y Vivienda del año 2000 -,7 más del 70\% ${ }^{8}$ de esta población sigue viviendo en el medio rural, sin que las condiciones de la producción hayan variado significativamente. Hoy, alrededor del $60 \%$ de las tierras se encuentran en manos del sector social y, sin embargo, los campesinos viven una de las peores crisis de los últimos años, esto demuestra que la tierra por sí misma, en manos de los campesinos, no resuelve el problema del subdesarrollo. Asimismo, estamos en presencia de una recomposición de las clases sociales en el campo chiapaneco: las viejas clases sociales, ancladas en la producción de café, en la explotación del bosque y la ganadería bovina, se encuentran en crisis, pero también los campesinos se encuentran inmersos en ella, en parte porque asimilaron el mismo patrón productivo: la gran mayoría de productores de café son campesinos y la ganadería bovina, que genera muy pocos empleos, se ha convertido en una de las actividades predominantes en los ejidos, junto con el cultivo del maíz.

\section{Crisis de producción y \\ crisis de los productores}

El campo chiapaneco, a pesar de haber presentado una relativa recuperación durante los años 1999 y 2000, se mantiene en niveles críticos: uno de los sectores más golpeados por las crisis de los precios internacionales es el café, la segunda actividad más importante, después del maíz, por la generación de valor y de empleos.

Por mucho tiempo, uno de los ejes de la economía agraria chiapaneca fue-

${ }^{7}$ El Conteo de Población 2005 revela que Chiapas cuenta, ahora, con 4,256,000 habitantes, es decir, 335,485 más que hace cinco años.

${ }^{8}$ Tomamos como criterio de ruralidad a las poblaciones que viven en localidades menores de 15 mil habitantes. 
ron las plantaciones cafetaleras. A partir de 1990, la situación cambió radicalmente debido a las modificaciones del sistema de cuotas en el mercado internacional. La regulación del mercado que ejercía la Organización Internacional del Café (orc) fue abandonada a mediados de 1989, lo cual generó inestabilidad en los precios y una caída paulatina como consecuencia de la saturación del mercado y del control de los procesos de comercialización por las empresas multinacionales. Después de cinco años consecutivos de bajos precios, que iniciaron en 1989, se logró una recuperación satisfactoria a partir de 1995; sin embargo, la bonanza pronto terminó, en 1997 comienza un nuevo ciclo de precios bajos y, hoy, los productores todavía no logran reponer los costos de producción, mucho menos obtener ganancias a pesar de la significativa recuperación que se observó en el ciclo cafetalero 2004-2005.9

Evolución del valor de las exportaciones de café

Valor (miles de dólares)

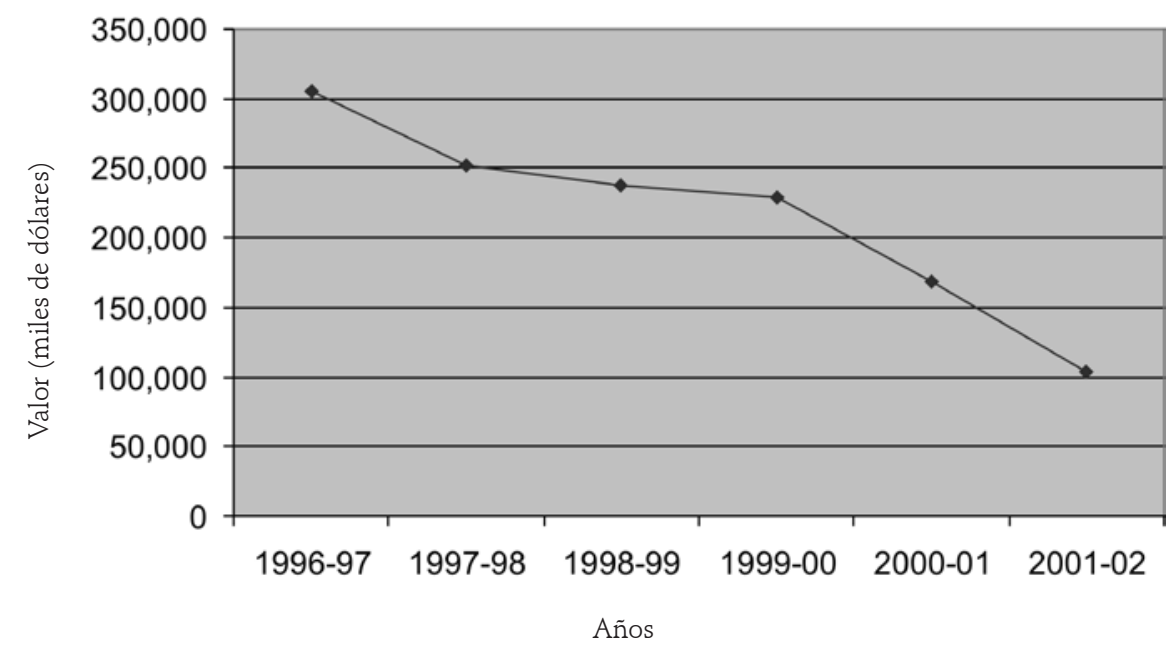

La crisis del campo no se limita a la cafeticultura, aunque es en ésta donde se visibilizan sus efectos más dramáticos, también la producción de maíz — que, en términos de volumen, ha venido creciendo- ha sufrido una transformación

\footnotetext{
${ }^{9}$ En esta idea, Francies Maestries (2003), en su artículo "Crisis cafetalera y migración internacional en Veracruz», trata de demostrar una relación de causalidad entre la debacle de los precios internacionales del café, sus efectos en el deterioro de las condiciones de ingresos y de vida de los productores y el incremento en los flujos migratorios internacionales de los veracruzanos. Para el caso de Chiapas, las repercusiones de la crisis del café han sido mayores debido, por una parte, a que ocupa el primer lugar en la producción nacional de este grano y, segundo, que es el estado con menor grado de industrialización en el país.
} 
significativa en su estructura y localización geográfica. El cambio de subsidios de indirectos a directos provocó que muchos productores ubicados en tierras de alta productividad, que se beneficiaban con la política de incentivos a la productividad, salieran del mercado y su lugar fuera ocupado por productores de subsistencia que cultivan hasta cinco hectáreas. Incluso se puede ver, claramente, un aumento en la superficie cosechada de maíz en regiones de economía campesina que producen para la subsistencia y destinan los excedentes al mercado.

Durante el periodo 1994-2003, la producción de maíz mostró un crecimiento sostenido y la superficie cosechada aumentó en 32 mil hectáreas, un promedio de 3 mil por año. El incremento en la superficie hizo que la producción pasara de 1.5 millones de toneladas, en 1994, a poco más de 2 millones en el 2003. En buena medida, este comportamiento se explica por los subsidios otorgados por el PROCAMPO. Este programa provocó la apertura de nuevas áreas de cultivo y desincentivó las antiguas regiones que producían para el mercado, en particular, los distritos de Comitán, Villaflores y Tapachula redujeron la superficie cosechada en casi 34 mil hectáreas en el periodo 1996-2002. Estos distritos, cuya producción se dedicaba al mercado, pasaron de aportar el $40.6 \%$ de la superficie cosechada, en 1996, a 35.7\% en el año 2002. Los datos muestran no sólo la relocalización de la producción de maíz, sino también el cambio de las áreas de alta productividad por tierras de baja productividad que, con los años, tenderán a perder importancia. La tendencia decreciente de la productividad, asimismo, está asociada a una disminución del monto real de los subsidios directos: mientras que, en 1995, los productores recibieron 919 pesos, en el año 2002 el monto fue de sólo 714 pesos.

CUADRO 3

Valor bruto de la producción de los cultivos cíclicos

\begin{tabular}{|c|c|c|}
\hline AÑo & VALOR (MILLONES DE PESOS) & ÍNDICE DE CRECIMIENTO \\
\hline 1999 & 3,874 & 100.00 \\
\hline 2000 & 3,900 & 100.67 \\
\hline 2001 & 3,339 & 86.00 \\
\hline 2002 & 3,522 & 103.13 \\
\hline 2003 & 3,951 & 101.98 \\
\hline
\end{tabular}

Fuente: SAGARPA, Delegación Chiapas, Centro de Estadística agropecuaria; Secretaría de Desarrollo Rural, Difusión de Acciones del Sector Agropecuario 1998-2000. Tomado de Salazar, Pablo (2004), Cuarto Informe de Gobierno.

Si consideramos el comportamiento del valor bruto de la producción de los cultivos cíclicos, podemos tener una idea más próxima a la realidad del campo. A 
partir de las cifras oficiales que se muestran en el cuadro tres, se puede observar que la situación de la agricultura se mueve en un escenario crítico, pues en los últimos cuatro años (2000-2003) no se registra una mejoría en los precios —que se expresa en el comportamiento del valor de la producción- pues, en términos nominales (sin descontar la inflación), lejos de presentar aumentos se registra, más bien, una tendencia decreciente, cuyo nivel más bajo se observó en el año 2001, al tener un índice de $-14 \%$.

Aunque el análisis que hace el gobierno de Chiapas, en torno al valor bruto de la producción, es muy optimista — al indicar que «la derrama económica generada por los cultivos cíclicos, como maíz, frijol, tomate, arroz, cacahuate, soya, sorgo, entre otros, se incrementó a una tasa media anual de 14.4\%» (Salazar, 2004: 177) - , lo cierto es que las propias cifras oficiales demuestran lo contrario. El gobierno admite, sin embargo, que en lo que se refiere a superficie cultivada, en lugar de haber un aumento se registró una disminución:

En cuanto a superficie cosechada, la tendencia se mantuvo casi estacionaria; sin embargo, mientras en 1997 al 2000, el promedio anual fue de 1 millón 153 mil 285 hectáreas, de 2002 a 2004 registró una caída de 2.6\%, pasando de 1 millón 123 mil 216 hectáreas en promedio anual. Esto, debido a factores como los efectos del Tratado de Libre Comercio, disminución de los subsidios al campo, incremento de los costos de producción, el desmantelamiento de la Conasupo, bajos rendimientos por falta de semillas mejoradas e inadecuada utilización de insumos, el desaliento de los productores por la baja en los precios, entre otros. En este año [2004] esperamos recuperar el valor de la producción y mejorar el ingreso de los productores [...] (Salazar, 2004: 177)

Las cifras oficiales no permiten hacer un análisis detallado sobre la situación que guardan algunos cultivos de importancia económica, como es el caso del plátano, un producto tradicional que ha contribuido, significativamente, al valor de la producción agrícola, pero también a la generación de empleos, sobre todo de migrantes centroamericanos. El plátano ha venido enfrentando, en los últimos años, una caída en los precios, como consecuencia de la sobreproducción en el mercado internacional y del control que ha ejercido la transnacional Chiquita Banana, al grado que, hoy, la mayoría de los productores se encuentran en una situación difícil. Los datos indican que la superficie cosechada en 1994 fue de 21,514 hectáreas y, para el año 2002, de 22,098, lo que indica un incremento de 583 hectáreas pero, contradictoriamente, se reporta una producción menor para el último año de poco más de 175 mil toneladas.

Otros cultivos comerciales también presentan problemas de producción: tal es el caso del mango que, en los últimos años, ha venido enfrentando un serio problema técnico que está repercutiendo en los niveles de productividad y de producción. En 1995 se obtuvieron 187 mil toneladas y, en el 2003, sólo se generaron 
130 mil. Los efectos de la crisis que enfrentan los tres productos comerciales más importantes de Chiapas (café, plátano y mango) repercuten severamente en la economía del estado, pues, en conjunto, generan un valor equiparable al de la suma del maíz y el frijol: 265 millones de dólares producto de los primeros, en tiempos de bajos precios, frente a 375 millones de dólares de los últimos, con la diferencia que los cultivos de plantación sólo ocupan 280 mil hectáreas, mientras que los granos básicos abarcan más de un millón de hectáreas.

Las actividades pecuarias y forestales también presentan problemas: la ganadería bovina, que desde 1988 había mostrado un agotamiento en su modelo de crecimiento extensivo, fue la más afectada con el levantamiento armado. De nueva cuenta, las cifras oficiales no revelan la magnitud del problema: en 1994, la población ganadera bovina era de, aproximadamente, 3 millones de cabezas y, en 1997, había bajado a 2.5 millones. Para entonces, las invasiones de tierras estaban por todas partes, pero los municipios más conflictivos se localizaban en zonas de más reciente apertura a la actividad ganadera, Palenque, Salto de Agua, Ocosingo, Altamirano. En estos municipios, la ganadería prácticamente desapareció como actividad económica en manos privadas. Algunas estimaciones consideran que, en los primeros tres años de conflicto, el hato ganadero había descendido a la mitad; muchos ganaderos sacaron sus semovientes a otros estados de la República mexicana, ante el temor de ser invadidos en sus propiedades. Las cifras de 2002 reportan una población bovina de poco más 2.7 millones de cabezas de ganado, lo que estaría reflejando un proceso de recuperación, pero todavía sin alcanzar el número que se tenía al inicio del movimiento zapatista.

En lo que respecta a la producción forestal maderable, que por cierto es la actividad que presenta las estadísticas menos consistentes, sobre todo porque no se incorporan estimaciones de la parte que se produce de manera clandestina, resulta interesante observar el aumento de la producción a partir del conflicto zapatista. Hay que recordar que antes del conflicto, el gobierno de Patrocinio González Garrido había decretado la veda forestal, una medida cuestionable jurídicamente porque es de competencia del gobierno federal. ${ }^{10}$ En este contexto, se puede decir que la actividad forestal se beneficia con el movimiento armado porque se rompe, de facto, la prohibición de cortar árboles.

Las medidas impuestas por el gobierno de Patrocinio González provocaron la caída de la producción; sin embargo, al estallar el conflicto se origina un rompimiento, de hecho, de la prohibición para cortar árboles y, en 1994, las estadísticas oficiales reportan una producción de 41 mil metros cúbicos de madera en rollo, cifra que contrasta, notablemente, con la de 1993, que fue la más baja en la his-

${ }^{10}$ Véase Daniel Villafuerte, María del Carmen García y Salvador Meza (1997), La cuestión ganadera y la deforestación. Viejos y nuevos problemas en el trópico y Chiapas, Tuxtla Gutiérrez, Universidad de Ciencias y Artes de Chiapas. 
toria forestal de Chiapas. A diez años del movimiento zapatista, la producción forestal se ha mantenido en constante crecimiento de tal forma que, ya para el 2002, se registra una producción de 187 mil metros cúbicos, lo que equivale a 4.6 veces más de lo reportado en 1994 y poco más de ocho veces de la cifra de 1993. Esto sin contar la tala clandestina en la llamada zona de conflicto (especialmente en Ocosingo y Altamirano) que, pese a los esfuerzos del gobierno de Chiapas, no se ha logrado detener.

La producción de madera en rollo, lejos de considerarse como un proceso de mejora económica, es un reflejo de la crisis del campo. Es, para decirlo de otra manera, un indicador del persistente modelo de producción extractiva que ha caracterizado a la economía chiapaneca desde hace más de 100 años. Es una actividad en la que, para los dueños del recurso, la mayoría campesinos, no significa ninguna inversión financiera, basta con tener una motosierra. Hay que decir, además, que los proyectos impulsados por los gobiernos federal y estatal, bajo la divisa de la sustentabilidad promovida por el Banco Mundial, no han logrado detener el proceso acelerado de deterioro que sufren los bosques y selvas de Chiapas.

En los últimos años, Chiapas ha venido padeciendo los problemas derivados de su estructura económica y de los múltiples rezagos en materia de desarrollo social y político. A esto se suma el contexto de la economía nacional, cuyo modelo se ha traducido en la escasez de inversión productiva y en el abandono, por parte del Estado, de la conducción del proceso de desarrollo. La ausencia de un proyecto propio, consensuado con los actores económicos y sociales del estado, ha llevado a que la política gubernamental siga los mismos lineamientos marcados por el gobierno federal, al enfocar sus esfuerzos en la promoción de Chiapas como un espacio para la inversión de capital nacional y extranjero. A pesar de todo, la Inversión Extranjera Directa (IED) ha sido muy escasa en la entidad: en 1994 y 1995 se registra una cifra promedio de 400 mil dólares, luego, en 1996 se incrementa a un millón para, en seguida, mantenerse en 400 mil durante los años 1997 y 1998. En 1999 y 2000 se registró la mayor entrada de IED de los últimos años, con montos de 3.3 y 2.2 millones de dólares respectivamente.

En el año 2001, la IED fue negativa en 0.9 y, para el año 2002, se registró un saldo positivo de 2.2 millones de dólares; sin embargo, para el 2003 vuelve a ser negativa, en $0.1 \%$. En resumen, la IED acumulada durante el periodo 1994-2003 fue de 8.94 millones de dólares, una cantidad insignificante frente a poco más de 127 mil millones que ingresaron al país en el mismo periodo. ${ }^{11}$ Estas cifras hacen evidente el poco interés que tiene el capital extranjero en invertir en Chiapas, dada la existencia de fuertes rezagos en infraestructura, escasa mano de obra calificada y la fragilidad de las condiciones políticas.

${ }^{11}$ Véase Secretaría de Economía, Subdirección de Inversión Extranjera, Inversión Extranjera Directa, 2003. 
Empleo, subempleo, pobreza y

desigualdad en el medio rural

La poca inversión productiva, tanto pública como privada, está llevando a una crisis de empleo, tanto en el campo como en las ciudades de mayor tamaño, a pesar de que en estas últimas se concentran la mayor parte de los establecimientos comerciales y de servicios. Es el caso de Tuxtla Gutiérrez, pero que bien puede generalizarse al resto de las ciudades de importancia como Tapachula, San Cristóbal de Las Casas y Comitán: en el año 2000, Tuxtla Gutiérrez concentró 11.1\% de la población de la entidad y $13.9 \%$ de la PEA, lo que revela el enorme peso que tiene en la dinámica económica de la entidad. Estos datos hacen, de Tuxtla Gutiérrez, un espacio de observación relevante en relación con los cambios de la actividad económica.

En el año 2000, la tasa general de desempleo abierto, en Tuxtla Gutiérrez, fue de $2.4 \%$, equivalente a $4,053.7$ personas desocupadas. Durante los años 2001 y 2002 la cifra se incrementó a 3.1\% y, para el 2003, se registra un ligero repunte para quedar en 3.2\%, lo que se traduce en alrededor de 5,500 personas desempleadas. A este fenómeno, por sí mismo significativo de la crisis económica, se añade la precariedad del empleo que se refleja en los siguientes indicadores: de la fuerza laboral empleada en Tuxtla Gutiérrez, durante el periodo 1992-2003, el 25\% ganó menos de un salario mínimo y trabajó más de 48 horas a la semana; otro indicador ilustrativo de la precariedad laboral es el hecho que, 55\% de los ocupados, no tuvieron prestaciones sociales durante el periodo analizado; también resalta que el 30\% de los trabajadores asalariados no gozaron de prestaciones. Además, habría que señalar que casi el $50 \%$ de los trabajadores ocupados se emplean en establecimientos de entre uno y cinco personas. ${ }^{12}$

A lo largo de la última década — que va de 1990 al 2000—, las condiciones de vida de la gran mayoría de la población chiapaneca no han cambiado. A la situación estructural se le añade el entorno generado por las políticas gubernamentales de corte neoliberal, las cuales se traducen en una tendencia a la disminución del gasto real y la inversión en el ámbito de la economía. Esto explica el por qué el estado de Chiapas sigue ocupando el primer lugar en pobreza y marginación en todo el país. Según las cifras censales, la población aumentó, en el periodo indicado, en poco más de 710 mil habitantes y el nivel de pobreza también creció: en 1990, la población que ganaba hasta dos salarios mínimos representó el 61\% y, en el año 2000, la proporción subió a 76\% (cuadro cuatro). En el campo, la situación es aún más crítica: el porcentaje de la población ocupada sin ingresos había subido a $40.7 \%$ y, del grupo que declaró ingresos, $74.5 \%$ obtuvo menos de un salario

\footnotetext{
12 Véase Encuesta Nacional de Empleo, INEGI, 2003.
} 
mínimo, lo cual, sumado al $16.2 \%$ de los que obtuvieron entre uno y dos salarios mínimos, nos informa que un $90.7 \%$ de la población laboral en el campo se encontraba en condiciones de pobreza y pobreza extrema, lo que estaría indicando un proceso brutal de pauperización de la población rural, mayor al registrado en el año de 1980.

\section{CUADRO 4}

Población total, indicadores socioeconómicos, índice y grado de marginación y lugar que ocupa Chiapas en el contexto nacional, 2000

\begin{tabular}{|c|c|c|}
\hline Población total & CHIAPAS & NACIONAL \\
\hline \% de población analfabeta de 15 años o más & $3,920,892$ & $97,483,412$ \\
\hline \% de población sin primaria completa de 15 años o más & 22.94 & 9.46 \\
\hline $\begin{array}{c}\text { \% de ocupantes en viviendas sin drenaje } \\
\text { ni servicio sanitario exclusivo }\end{array}$ & 50.31 & 28.46 \\
\hline \% de ocupantes en viviendas sin energía eléctrica & 19.33 & 9.90 \\
\hline$\%$ de ocupantes en viviendas sin agua entubada & 12.01 & 4.79 \\
\hline \% de viviendas con algún nivel de hacinamiento & 24.99 & 11.23 \\
\hline \% de ocupantes en viviendas con piso de tierra & 65.03 & 45.94 \\
\hline \% de población en localidades con menos de 5,000 habitantes & 61.21 & 30.97 \\
\hline \% de población ocupada con ingreso de & 74.79 \\
\hline hasta dos salarios mínimos & 75.89 & 50.99 \\
\hline Índice de marginación & 2.2507 & \\
\hline Grado de marginación & Muy alto & \\
\hline Lugar que ocupa en el contexto nacional & 1 & \\
\hline
\end{tabular}

Fuente: estimaciones de CONAPO, con base en el XII Censo General de Población y Vivienda 2000.

Aunque algunos indicadores de marginación mostraron cierta mejoría durante los años noventa - como, por ejemplo, el porcentaje de viviendas con servicios de drenaje, agua entubada y energía eléctrica-, otros mostraron un deterioro evidente, como es el caso de la población de 15 años y más sin primaria completa que pasó de 39\%, en 1990, a poco más de 50\% en el año 2000. En relación con los mismos indicadores en el ámbito nacional, Chiapas se mantuvo bastante rezagado, lo que provocó que permaneciera como el estado más marginado del país. Si comparamos el índice de marginación construido a partir de los datos censales, con los criterios utilizados para la elaboración del índice de desarrollo humano (IDH) del Programa de las Naciones Unidas para el Desarrollo (PNUD, 
2005), observamos que, mientras con el primero, el estado de Chiapas resultó con un grado de marginación muy alto, con el IDH se ubicó en un grado de desarrollo humano medio alto y ocupó el último lugar de las entidades federativas. Lo más relevante de esta comparación es que, con ambos criterios, no hay diferencia en el lugar que ocupa el estado de Chiapas en materia de desarrollo social en el país: el último lugar.

Un estudio reciente, elaborado por el Banco Mundial, confirma esta apreciación al señalar que, «Según cualquier medida disponible, Chiapas, Oaxaca y Guerrero son considerablemente más pobres que el resto de México. Si se calcula conforme al ingreso y consumo, aproximadamente el $67 \%$ de la población de esos estados vive bajo la línea de pobreza, en comparación con el 42\% al 45\% para el conjunto del país. Los hogares de los estados del Sur tienen un nivel de ingreso per cápita equivalente a un poco más de la mitad (54\%) del promedio nacional» (Wodon, López y Siaens, 2004).

\section{MIGRACIÓN INTERESTATAL E INTERNACIONAL}

EN CHIAPAS

A partir de la segunda mitad del siglo xx, Chiapas comienza una etapa de intensas migraciones internas y hacia otros estados del país. En lo interno, se intensifican los procesos de colonización espontánea y dirigida a diversos territorios, principalmente a la Selva Lacandona. También, la movilización temporal de trabajadores agrícolas hacia la región del Soconusco, sobre todo para la cosecha de café, es significativa hasta principios de los años setenta. Lo mismo ocurre con el desplazamiento de la población indígena de Los Altos de Chiapas hacia tierra caliente de los Valles Centrales. La construcción de las grandes presas hidroeléctricas, que comienzan a mediados de los años cincuenta y terminan en los años ochenta, constituyó, de igual manera, un factor de movimientos de población.

En lo que respecta a la migración interestatal, la población chiapaneca empieza a desplazarse, particularmente a principios de los años setenta, hacia las zonas petroleras de Tabasco y, posteriormente, hacia Cancún, donde comienza a desarrollarse el polo turístico más importante del país. Cuantitativamente, los saldos migratorios presentaron un cambio sustancial durante el periodo 19501970, en el primer año se registró un saldo de -4,969 en tanto que, para el último, la cifra era de $-55,037$, lo que significa que, en estos treinta años, se registró un incremento en el saldo migratorio de poco más de 1,000\% (Villafuerte et al., 1999). En los siguientes treinta años, aunque el incremento sólo fue de $300 \%$, en cifras absolutas significó un saldo migratorio negativo de 228,957 personas.

En el umbral del siglo xxi comienza un nuevo ciclo de migraciones, esta vez no se trata sólo de desplazamientos hacia otros estados del país, sino a Estados Unidos y Canadá. En la migración interestatal se produce una diversificación 
significativa: si bien, siguen predominando, como lugar de destino, Tabasco, el Estado de México, el Distrito Federal y Quintana Roo, comienzan a figurar, en orden de importancia, las entidades de Baja California, Jalisco, Tamaulipas, Chihuahua, Nuevo León y Sonora.

A propios y extraños ha sorprendido que la emigración de chiapanecos, al norte del país y a Estados Unidos, sea hoy una variable fundamental no sólo para explicar la relativa estabilidad de la sociedad chiapaneca tras el conflicto neozapatista de 1994, sino, también, para cualquier propuesta de desarrollo económico en sus vertientes estatal, regional y local. Como ya hemos apuntado arriba, la movilidad con fines laborales, si bien ha sido una de las características de la población chiapaneca, se trataba, hasta muy recientemente, de una migración interna y, la migración interestatal, se orientaba a los estados vecinos así como del centro del país. Y es que la emigración de chiapanecos, con destino a los Estados Unidos y a los estados del norte del país, es relativamente reciente, articulándose a los flujos espectaculares que registra la migración mexicana a Estados Unidos, de los años ochenta y noventa, como producto de las crisis económicas, manifiestas en el decremento del ingreso per cápita en los ochenta, en un crecimiento mínimo de éste en los noventa y en la pérdida de miles de empleos, así como el subsiguiente crecimiento del desempleo y subempleo (Papail y Arroyo, 2004: 29).

En este contexto, y de acuerdo a las estadísticas oficiales, es hasta los noventa cuando se hace perceptible una serie de cambios en su dinámica que, si bien, es consistente con la tendencia de mayores flujos migratorios, no registra del todo el súbito incremento de la migración de chiapanecos de los últimos cinco años. En 1990, por lugar de nacimiento, el saldo neto migratorio fue negativo, de -4.0 por ciento; en el 2000, esta tendencia continúa, al situarse en -5.7 por ciento. Este hecho se refleja en el incremento de emigrantes que, en los mismos años, pasó de 7.3 a 9.0 por ciento respectivamente (INEGI, 2002).

En 2000, más de 300 mil chiapanecos se desplazaron a diversos estados del país: 20,214 al estado de Baja California; 31,818 lo hicieron a Quintana Roo; y cerca de 20,500 arribaron a Tamaulipas, Chihuahua, Sonora, Sinaloa y Coahuila. El Estado de México fue el destino de 49,990 chiapanecos (InEGI, 2002; Gobierno del estado de Chiapas, 2004; Pimienta y Vera, 2005). Un hecho a destacar es la incorporación, a los circuitos migratorios, de las mujeres. En el 2000, el INEGI registró que 178,954 mujeres chiapanecas se incorporaron a los flujos migratorios, más del 80\% de éstas con una edad que va de los 15 a los 34 años (INEGI, 2002, Pimienta y Vera, 2005).

Los resultados del Censo General de Población y Vivienda del 2000 no reflejan el peso que, creemos, hoy juega la población chiapaneca migrante internacional. En los últimos cinco años, los migrantes internacionales representaron 0.3 por ciento de la población total y, de este universo, el 79 por ciento continúa viviendo en el extranjero. Del total de la población migrante internacional, 79.2 por ciento son hombres y, 20.8, mujeres. Con respecto a la edad de los migrantes, 
se indica que el 80.7 por ciento es población joven (de 15 a 34 años); en atención a la dirección de los flujos, estamos hablando de una migración unidireccional, pues 93.3 por ciento de los migrantes eligió los Estados Unidos, aunque empieza a cobrar importancia Canadá, país al que se dirige un grupo importante de trabajadores agrícolas temporales.

Un indicador parcial, de la importancia que están adquiriendo los flujos migratorios a Estados Unidos, es el incremento de la matricula consular, que, de acuerdo con el gobierno de Chiapas, es de 20,463 personas (El Heraldo de Chiapas, 20 de agosto de 2005). Un comparativo realizado por el gobierno del estado indica que, entre 2001 y 2003, el número de matrículas consulares expedidas pasó de 4,092 a 9,852 (Gobierno del estado de Chiapas, 2004). Otra fuente que nos aproxima a la magnitud del fenómeno migratorio es la Encuesta sobre Migración en la Frontera Norte de México (EMIF): entre 1994-1995 y 1998-1999, el número de emigrantes chiapanecos devueltos por la patrulla fronteriza pasó de 6,129 a 13,372 personas. Sin embargo, ya para el periodo 1999-2000, el número de emigrantes chiapanecos deportados fue de 30,523. De ésta última cifra, 12.6\% fueron mujeres (Gobierno del estado de Chiapas, 2004; Encuesta sobre Migración en la Frontera Norte de México, 1998-1999).

Para el año 2000, Burke registra la presencia de mayas yucatecos y chiapanecos en la Bahía de San Francisco, California: "Mientras que los inmigrantes de los estados mexicanos de Michoacán y Zacatecas cuentan con una tradición de muchas décadas en el trabajo temporal en el área de la bahía, en años recientes más de 6,000 inmigrantes de Yucatán y Chiapas, muchos de los cuales crecieron hablando maya o tzotzil, habían llegado a dicha área» (Burke, 2003:375).

Frente a la ausencia de indicadores más precisos, que den cuenta de la magnitud real del éxodo de chiapanecos a los estados del norte, pero, particularmente, hacia Estados Unidos, recuperamos la información del Banco de México sobre los montos de las remesas. En 1990, Chiapas ocupaba el lugar 29 entre las entidades federativas que recibieron remesas familiares; para 1995, pasa al lugar 27; sin embargo, para 2001 ya ocupaba el lugar 15 y, para el 2003, llega al sitio 12, muy cerca del estado de Zacatecas que, para el mismo año, ocupó el lugar número 11. La tendencia es hacia el crecimiento pues, en 2004, rebasa al estado de Zacatecas, al obtener poco más de 500 millones de dólares, ${ }^{13}$ una cifra superior en $42 \%$ a los

${ }^{13}$ Los montos de remesas, reportados por el Banco de México, han sido cuestionados, no tanto por que se considere que estén mal, sino porque se piensa que el concepto de remesa familiar no se corresponde con las cantidades proporcionadas por la autoridad monetaria del país. El Centro de Estudios Monetarios para América Latina (CEMLA) encabeza una investigación para estimar, con mayor precisión, el monto de las remesas familiares. Las discrepancias se explican por el siguiente razonamiento: "En las estadísticas sobre remesas el Banco de México tiene muy bien las estimaciones que se basan en los registros derivados de los medios modernos, como son las transferencias electrónicas, y subestima los tradicionales como el correo, el efectivo y en especie. Para la autoridad 
ingresos obtenidos por la actividad turística y equiparable a la suma del valor de los granos básicos, así como a la de los tres principales productos comerciales de exportación (café, plátano y mango). A esto hay que agregar las cantidades de dinero que los migrantes Chiapanecos envían a sus lugares de origen vía giros telegráficos que, aún cuando no contamos con las cifras sobre los montos, el aumento en el número de piezas es revelador: durante el periodo 1996-2002, el número de giros internacionales se incrementó en 44.5\%, al pasar de 26 mil 222, en 1996, a 37 mil 888 en el segundo año, destacando los municipios fronterizos de Benemérito de las Américas, Comitán, Frontera Comalapa y Suchiate, cuya suma representó 36.4\% del total de giros.

CUADRO 5

Chiapas. Remesas familiares, según trimestre y total por año

(millones de dólares)

\begin{tabular}{|c|c|c|c|c|c|}
\hline AÑO & TRIMESTRE I & TRIMESTRE II & TRIMESTRE III & TRIMESTRE IV & TOTAL \\
\hline 1995 & ND & ND & ND & ND & 19.8 \\
\hline 2001 & ND & ND & ND & ND & 223.3 \\
\hline 2003 & 73.0 & 92.3 & 99.5 & 96.1 & 360.9 \\
\hline 2004 & 90.2 & 138.4 & 139.2 & 132.5 & 500.3 \\
\hline 2005 & 123.1 & 170.2 & 185.6 & 176.4 & 655.3 \\
\hline
\end{tabular}

ND: no hay datos.

Fuente: Banco de México, Indicadores Económicos y Financieros.

Otra fuente de recursos son los ingresos de los jornaleros chiapanecos que, de manera temporal, emigran a Canadá, en el marco del programa de trabajadores agrícolas temporales México-Canadá, que funciona hace más de diez años bajo la coordinación de la Secretaría de Relaciones Exteriores y la Secretaría del Trabajo y Previsión social. Un creciente número de campesinos chiapanecos ha emigrado de forma temporal, con contratos de ocho meses, a Canadá para trabajar en diversas actividades relacionadas con la agricultura. De acuerdo con Teresa Román, ex delegada de la Secretaría de Relaciones Exteriores en Chiapas, en el 2004 se otorgaron 10,500 pasaportes en el país y se estimaba un incremento para el 2005. ${ }^{14}$ Para el caso de la entidad, la cifra es de, aproximadamente, 500 jornaleros, si tomamos en cuenta que un trabajador puede ganar, en promedio, 400 dólares a la semana, 
podemos estimar que la masa de salarios obtenida por los jornaleros chiapanecos, durante los ocho meses de contrato, es de siete millones de dólares canadienses.

Como se puede apreciar en el cuadro cinco, la importancia de las remesas familiares es, a todas luces, relevante para Chiapas. Una mirada al pasado permite percatarnos que, a mediados de la década de 1970, la entidad ya figuraba dentro del grupo de estados que recibían remesas, aún cuando estas apenas significaban el 0.4\% del PIB, así lo revela un estudio realizado por Díez-Canedo (1980), donde se puede ver que Chiapas recibió, en 1975, poco más de 7 millones de dólares, ${ }^{15}$ mientras que el piB para ese año fue de 18,350 millones de pesos.

\section{CUADRO 6}

Comparativo de diversas fuentes de ingreso frente a las remesas familiares (millones de dólares)*

\begin{tabular}{|c|c|c|c|c|}
\hline & $\begin{array}{c}\text { INGRESOS } \\
\text { POR TURISMO }\end{array}$ & $\begin{array}{c}\text { INVERSIÓN } \\
\text { EXTRANJERA DIRECTA }\end{array}$ & $\begin{array}{c}\text { SUBSIDIOS AL CAMPO } \\
\text { (PROCAMPO) }\end{array}$ & $\begin{array}{c}\text { REMESAS } \\
\text { FAMILIARES }\end{array}$ \\
\hline 2002 & 169.1 & 2.2 & 76.3 & N.D. \\
\hline 2003 & 256.7 & 1.4 & 85.3 & 360.9 \\
\hline 2004 & 289.4 & 3.4 & 92.8 & 500.3 \\
\hline 2005 & 340.3 & 1.4 & N.D. & 655.3 \\
\hline Total & $1,055.5$ & 8.4 & 254.4 & $1,516.5$ \\
\hline
\end{tabular}

Fuentes: (1) Salazar, Pablo, Cuarto y Quinto informe de Gobierno, Tuxtla Gutiérrez, Chiapas, 2004 y 2005; (2) Secretaría de Economía, Dirección General de Inversión Extranjera Directa; (3) INEGI, Anuario Estadístico de Chiapas, varios años;

(4) Banco de México, Indicadores Económicos y Financieros.

"Para la conversión a dólares se uso un tipo de cambio promedio de 10.5 pesos por dólar.

Si nos atenemos al monto de remesas, aún con los problemas de cálculo que presentan, podemos tener una idea aproximada de la importancia del flujo migratorio de chiapanecos a Estados Unidos. La cantidad promedio de dinero enviada por migrante en el año 2005, estimada por Alducin (2005: 46), está en los 270 dólares mensuales, en tanto que, la del Banco de México, se sitúa en los 340 dólares. Si aceptamos como válida la cifra de remesas del Banco de México (655 millones de dólares) y tomamos como referencia el dato de Alducin, estaríamos

\footnotetext{
${ }^{15}$ Si consideramos que, para ese año, el tipo de cambio era de 12.50 pesos por dólar, podemos decir que el monto de remesas, medido en pesos, fue de 87.9 millones de pesos.
} 
hablando de 202 mil chiapanecos en Estados Unidos, de manera que 4.74\% de la población chiapaneca estaría en Estados Unidos. Aunque estas cifras no están fuera de toda realidad, deben tomarse, únicamente, como referencia, pues no se cuenta con datos censales actualizados sobre el número de migrantes en Estados Unidos; además, las cifras de remesas del Banco de México han sido cuestionadas, aunque tampoco se ofrece un cálculo alternativo, veamos:

[...] De acuerdo con el Banco de México, el estado de Chiapas recibió 500 millones de dólares que, según el censo mexicano y las fuentes estadísticas, se distribuyeron cuando mucho en 13 mil hogares, es decir, cada hogar chiapaneco relacionado con la migración, en el escenario más optimista, recibió la increíble cantidad de tres mil dólares mensuales por este concepto [...] Si estos datos los contrastamos - sin ofender a los chiapanecos- con el tipo de mano de obra barata y poco calificada que de ese estado se inserta en el mercado laboral estadounidense, no hay cómo creer que todo ese dinero va a los hogares chiapanecos, por la simple y sencilla razón de que no hay cómo creer que los emigrantes chiapanecos ganan algo así como 15 mil dólares mensuales, para poder enviar tres mil dólares de remesas cada mes [...] (Santibáñez, 2005: 24).

La pregunta es «żse trata de un problema de cálculo de remesas familiares o del número de migrantes chiapanecos que trabajan en Estados Unidos?» El enigma puede resolverse si se tuvieran datos precisos de chiapanecos radicados en el vecino país del norte y, por supuesto, del dinero que gastan en manutención. En general, se piensa en los datos que proporciona el Censo de Población y Vivienda del año 2000, pero se alude a las remesas del año 2005, el problema es que no se pueden hacer cálculos con años diferentes. Pero, independientemente del dato sobre migrantes chiapanecos en Estados Unidos, no hay duda que la constatación empírica revela un aumento significativo de los flujos migratorios en los últimos diez años.

\section{CRISIS RURAL Y MIGRACIÓN}

Especialistas en el campo de la migración (Massey et al., 1991) indican que, en la configuración y dinámica migratoria, interviene una multiplicidad de elementos, destacando, en primer orden, los cambios estructurales sufridos entre las comunidades de origen y las de destino. En el estado de Chiapas, no hay duda de que la crisis rural y sus efectos, en el desplome del empleo y la agudización de la desigualdad social en el campo, son factores determinantes del crecimiento de los flujos migratorios. El segundo ciclo de la crisis del café terminó por consolidar el proceso de migración que se había iniciado en el primer ciclo, a tal grado que, en el año 2003, las remesas que enviaron los chiapanecos residentes en los Estados Unidos fueron del orden de los 360 millones de dólares, equivalentes al 3.6\% del 
PIB del mismo año ${ }^{16}$ y a tres veces más de lo obtenido por las ventas de café en el ciclo 2002-2003, monto sólo equiparable al valor originado en el ciclo 1996-1997, uno de los más altos de los últimos 15 años. ${ }^{17}$ Hoy, el fenómeno migratorio se ha convertido en uno de los problemas más indicativos de la crisis rural que vive Chiapas, pero también es, al mismo tiempo, un reflejo de los problemas estructurales que enfrenta la entidad. Un último indicador, significativo en este sentido, es la disminución de los trabajadores guatemaltecos temporales en el sector agropecuario de la entidad, quienes ahora prefieren seguir su camino hacia Estados Unidos. En efecto, un estudio del Instituto Nacional de Migración (2005) indica que, en el año 2000, ingresaron a Chiapas 69,036 trabajadores temporales documentados y, para el 2004, el flujo de trabajadores había disminuido a 41,894. Por el contrario, las detenciones de migrantes guatemaltecos que intentaron cruzar la frontera se incrementaron notoriamente: 67,336 en 2003; 94,404 en 2004; y 100,948 en $2005 .{ }^{18}$

Reconocemos, sin embargo, que la explicación de la dinámica migratoria reciente en la entidad es mucho más compleja y no puede atribuirse, exclusivamente, a la crisis rural y a la pobreza, rasgos persistentes desde tiempo atrás sin que se hubiese establecido una correlación con el fenómeno migratorio internacional, como ha ocurrido con el estado de Oaxaca y Guerrero, entidades que, junto con Chiapas, son las más pobres de la República mexicana. En este sentido, una hipótesis del por qué de la tardía incorporación de la zona sureste de México, a las corrientes migratorias internacionales, la han establecido Durand y Massey en los siguientes términos:

Muy posiblemente la explicación de por qué esta región no se había integrado de manera definitiva al flujo migratorio internacional se encuentra en dos factores. En primer lugar, el sistema de enganche operó exclusivamente para la migración interna y, en segundo término, la participación de la región durante el Programa Bracero fue mínima (0.95 por ciento). Es decir, no hubo un proceso externo de reclutamiento que diera inicio al fenómeno, no existió un detonante, un catalizador, como lo fue el programa Bracero en otras regiones (Durand y Massey, 2003: 89).

\footnotetext{
${ }^{16}$ De acuerdo con la información del Sistema de Cuentas Nacionales del INEGI, en el 2003, el PIB de Chiapas, expresado en pesos corrientes, fue de 106,101.4 millones y las remesas para el mismo año, convertidas en pesos en una proporción de 10.5 pesos por dólar, fueron de 3,780 millones de pesos. La magnitud de las remesas con respecto al PIB puede ser mayor si consideramos que los índices de inflación, en México, han sido mayores que los registrados en Estados Unidos, además, hay que tomar en cuenta la macro-devaluación del peso mexicano de finales de 1994.

${ }^{17}$ El valor estimado de la producción de café, para el ciclo 1996-1997, fue de 382 millones de dólares y, para el ciclo 2002-2003, de 108.8 millones de dólares (Véase Salazar, Pablo, Cuarto Informe de Gobierno, Tuxtla Gutiérrez, Chiapas, diciembre de 2004).

${ }^{18}$ Véase estadísticas del Instituto Nacional de Migración en la página web: ‘www.inami.gob.mx`.
} 
Durand y Massey (2003) consideran que las condiciones de marginación y pobreza no explican las migraciones. Argumentan: «como se sabe, la pobreza extrema no suele estar asociada con la migración internacional, debido a los altos costos monetarios que implica el viaje y el cruce de la frontera». En el caso de Chiapas, este es un punto que todavía no está muy claro. Hemos podido constatar, ciertamente, que una parte importante de la población joven y adulta, que se ha articulado al circuito migratorio internacional, no vive en situaciones de pobreza extrema, son pequeños productores o los hijos de éstos, que han resentido la crisis del café y de la agricultura en general, como es el caso de muchos migrantes de Tapachula y, en general, de las regiones Soconusco y Costa; son, también, personas de origen medio, cuyos pequeños negocios han quebrado y han tenido que enfrentar situaciones de embargo bancario o de particulares; asimismo, se trata de un sector reducido de profesionistas, especialmente maestros normalistas, que no alcanzan a solventar sus necesidades de reproducción social y biológica por haber enfrentado alguna situación crítica en el seno familiar, o jóvenes que han desistido seguir la vocación agrícola de sus descendientes, como ocurre en Frontera Comalapa y Chicomuselo.

Por otra parte, también hemos registrado casos de migración internacional en comunidades indígenas de las regiones Sierra y Altos que, a través de un mecanismo de préstamos, pueden financiar el viaje. Rus y Rus (2005) sostienen que, entre septiembre y agosto de 2005, veintitrés tzotziles de la comunidad Ch'ul Osil, municipio de Chamula, emprendieron el viaje a Estados Unidos; siete de ellos consiguieron dinero con el pollero de la comunidad, a una tasa de interés de $10 \%$ mensual; esto se repite en varias comunidades indígenas de Chiapas. Hermann Bellinghausen, observador de la realidad chiapaneca, ha señalado que «el espejismo del dólar es nuevo en Chiapas, pero ha causado furor entre la población más pobre». Bellinghausen refiere que «en los pueblos indígenas de la selva y la frontera se ha vuelto una verdadera (moda) unirse a la cuadrilla de pollos. En las afueras de Ocosingo, Comitán, Las Margaritas o La Trinitaria abundan oficinas de tijuaneros que ofrecen viajes a Tijuana y Altar «todos los miércoles, a precios económicos». Anuncian escalas en Tuxtla Gutiérrez, Oaxaca, Querétaro, San Luis Potosí, Zacatecas, Agua Prieta, Nogales, y absoluta seriedad» (La Jornada, 25 de enero de 2005).

En 1998, el huracán Mitch, con efectos más limitados que Stan, provocó un incremento significativo en las migraciones. En aquel momento, la industria maquiladora ofrecía empleos a los damnificados, incluso se pagaba el transporte a Tijuana, Mexicali y Monterrey, de manera que, entre octubre y diciembre de 1998, unos 35 mil chiapanecos habían emprendido el camino. El reciente huracán Stan (octubre de 2005), con efectos más devastadores que el Mitch, ${ }^{19}$ tendrá consecuen- 
cias mayores en los flujos migratorios que, ahora, se verán potenciados con las experiencias migratorias de años atrás y con la existencia de «agencias de viaje».

En entrevistas realizadas en los municipios fronterizos, encontramos algunos consensos: los primeros migrantes contaron con el apoyo de inmigrantes centroamericanos y utilizaron las redes así como organizaciones informales ya existentes. Contaron, también, con las ofertas de personas que llegaron directamente del norte del país, quienes ofrecieron garantías de trabajo y facilidades de tránsito. La primera experiencia fue la de trabajar en algún estado del norte y después, con un ahorro en mano, emigrar al vecino país.

Hoy ya es posible identificar algunas redes aún no sólidas, particularmente entre familiares y amigos, que posibilitan relaciones entre las comunidades de origen y las de destino. El alcance de estas redes se va fortaleciendo en la medida en que se incrementa el número de migrantes y, asimismo, conforme el fenómeno migratorio se va haciendo una práctica de continuidad. Estamos ante un desarrollo aún incipiente, pero importante, de redes familiares y no familiares que van adquiriendo un carácter más estable, lo que posibilita reconocer procesos migratorios acumulativos, que dan lugar a relaciones más estrechas de las actividades económicas y de las condiciones de vida entre las regiones de partida y las de llegada (Massey et al., 1991).

Cada vez se van incorporando nuevos municipios al proceso migratorio. En la Sierra y región Fronteriza: Amatenango de la Frontera, Siltepec, El Porvenir, Bejucal de Ocampo, Motozintla, Mazapa de Madero, Bella Vista, Chicomuselo, Frontera Comalapa y Las Margaritas. En el Soconusco y la Costa: Suchiate, Escuintla, Mapastepec y Tonalá. En Los Altos: San Juan Chamula, Zinacantán,

Sierra Madre de Chiapas-, en la costa fueron afectadas miles de hectáreas de cultivos, la carretera Arriaga-Tapachula fue destruida en los tramos principales y Tapachula quedó aislada del resto del país. En la primera semana de octubre de 2005, la historia se repite, pero ahora con un saldo de mayores proporciones, de vastas consecuencias sociales, económicas y políticas. Estimaciones preliminares advierten que el huracán Stan dejó miles de hectáreas de cultivo bajo el agua. Alfredo Moisés Ceja, presidente de la Asociación Mexicana de Exportadores de Café (AMEC), considera que los daños a la cafeticultura de la región se calculan en 780 mil sacos de 60 kilogramos, con un valor aproximado de 1,800 millones de pesos, equivalente a la mitad de lo que produce Chiapas. Se calculan que las pérdidas globales podrían estar en cerca de 185 millones de dólares, que incluyen la destrucción de cafetales, maquinaria, caminos y canales. Los municipios productores de café más afectados son Tapachula, Huixtla, Jaltenango y Motozintla; de la superficie cafetalera de Chiapas, que hace un total de 228 mil hectáreas, entre 150 mil y 170 mil están afectadas (Véase El Financiero, 10 de octubre de 2005). El café representa sólo una parte del problema que enfrentan los productores del Soconusco y de la Sierra. Hay que tomar en cuenta que otros cultivos fueron gravemente dañados, en particular la cosecha de maíz que sirve de sustento a miles de familias: las zonas afectadas producen entre 75 y 80 mil toneladas, por lo que ahora tendrán que depender del mercado. También hay que considerar que las familias necesitarán de dinero para reconstruir sus viviendas. En el municipio de Suchiate, uno de los más devastados por Stan, la agricultura fue arrasada, se estima, en más de 8 mil hectáreas de cultivo entre banano, maíz, soya, ajonjolí y sorgo. Este municipio es el mayor productor de banano, con alrededor de 5 mil hectáreas contribuye con $30 \%$ de la producción del estado, y emplea una gran cantidad de trabajadores guatemaltecos. 
Pantelhó y San Andrés Larraínzar. También aparecen nuevos itinerarios en el peregrinar de los chiapanecos: Nogales, Agua Prieta y Altar, la razón es que, desde 1998, se convirtieron en el paso más transitado, luego de que los lugares tradicionales de paso, como Tijuana, Tecate y Mexicali, fueron reforzados. Además, campesinos de los municipios de Arriaga, Cacahotán, Tonalá, Huixtla, Chamula y Villaflores se han enlistado en el programa de trabajadores temporales para permanecer ocho meses en Canadá. En este país, un jornalero puede obtener un ingreso semanal de 3,400 pesos, aproximadamente unos 400 dólares canadienses.

Una de las regiones pioneras en la «exportación» de migrantes es la Sierra: Frontera Comalapa, cabecera del municipio que lleva el mismo nombre, representa la intersección entre dos regiones de alta migración -la Fronteriza y la Sierra- En esta localidad se encuentran alrededor de 27 «agencias de viajes» que hacen el recorrido hasta Tijuana; en Frontera Comalapa se inicia el llamado corredor del migrante serrano, para seguir y parar en varios puntos de la serpenteante y estrecha carretera de la Sierra, hasta entroncar con la carretera costera.

Hoy, los Chiapanecos ya forman parte del mosaico rural y urbano de Estados Unidos. Georgia, Virginia, California, Nueva York, Florida, Arizona y Carolina del Norte son los principales lugares de destino de los migrantes chiapanecos. En el valle de San Joaquín, en el estado de California, donde la agricultura genera $30 \mathrm{mil}$ millones de dólares anuales, comienza a ser visible la presencia de indígenas tzotziles chiapanecos (La Jornada, 19 de junio, 2005). Chiapas aparece en las estadísticas migratorias, en las casas de migrantes y en las defunciones. Por ejemplo, la Casa del Migrante «Nazareth», ubicada en Nuevo Laredo, Tamaulipas, reporta la estancia de 271 chiapanecos a lo largo del año 2002 (Migrantes, julio-diciembre, 2004).

La estrategia laboral eventual, propia de un mercado segmentado y diferencial en atención a la particularidad de las labores realizadas, se ha desarrollado en los Estados Unidos y, hoy, atrae a los migrantes del sur de México. Una porción importante de la fuerza de trabajo de los chiapanecos rurales se inserta en este tipo de mercado laboral. Aunque no cambien, mayormente, sus condiciones de vida y de trabajo, estudiosos del fenómeno migratorio coinciden en reconocer un aumento de la inmigración residencial de familias indígenas nucleares del sur del México, entre ellos chiapanecos, en las ciudades de los estados del norte del país y en estados de la Unión Americana e, incluso, Canadá (Maier, 2003; Burke, 2004). ${ }^{20}$

La migración de chiapanecos responde, también, a la expansión de la economía de las entidades del norte de México y de Estados Unidos, en los sectores de la industria maquiladora, la construcción, los servicios, restaurantes y hoteles

${ }^{20}$ Elizabeth Maier sostiene que «La diáspora indígena mexicana actualmente se extiende desde Alaska, pasando por Canadá, Nueva York, Oregon, Washington, Texas, Wyoming, Arizona, Georgia, Nevada y California hasta Florida, en términos transfronterizos, diversificando los paisajes geográficos culturales de los centros urbanos y mercados laborales agrícolas a lo largo del país» (2003: 121). 
que demandan trabajadores eventuales y poco calificados. A este respecto, ya es posible dibujar un mapa migratorio en el que grupos de comunidades del mismo origen empiezan a establecerse, de manera permanente o más sistemática, en ciudades; por ejemplo, grupos de migrantes de Tapachula en San Diego, California; migrantes de Frontera Comalapa, al igual que de Huixtla, en Miami, Florida.

\section{REFLEXIÓN FINAL}

La crisis terminal del modelo de agricultura de plantaciones y de ganadería extensiva ha traído, consigo, una tendencia a la pauperización general, ya no se trata solamente de los sectores que, tradicionalmente, se han mantenido en el rango de pobres y pobres extremos, sino también de amplios grupos que, en otro momento, pudieron tener una situación mejor en términos de ingresos. Es una crisis estructural, provocada por el entorno macroeconómico y sectorial del país e internacional, cuyas exigencias de ajustes y productividad modifican los mercados laborales, incrementan los índices de desempleo y reducen los salarios (Mármora, 2002). En esta perspectiva, la migración internacional contemporánea de Chiapas está modulada por las articulaciones económicas entre México y Estados Unidos, particularmente por las interrelaciones de los procesos de trabajo y los mercados laborales de ambos países, en un contexto de creciente globalización de la producción (Canales, 2000). A pesar de la importancia que han tenido, y siguen teniendo, las migraciones internas, el fenómeno más notable y reciente de Chiapas es el éxodo de chiapanecos a los estados del norte de la República mexicana y, particularmente, a Estados Unidos.

El nuevo proceso migratorio internacional coincide con tres eventos de gran impacto que se presentan como un continuum, lo que hace que tengan un efecto acumulativo: la crisis de los precios internacionales del café (julio de 1989), el levantamiento armado del EzLn (enero de 1994) y los efectos del huracán Mitch (septiembre de 1998) sobre las zonas cafetaleras de la Sierra Madre y la Costa de Chiapas. Entre los ciclos cafetaleros 1996-97 y 2001-2002, debido a los bajos precios del aromático en el mercado internacional, se acumuló una pérdida de 540 millones de dólares. Durante el mismo periodo, la inversión realizada por el gobierno federal, vía Alianza para el Campo, fue por el equivalente a 32 millones de dólares, lo que da una idea de la proporción de los apoyos gubernamentales frente a las pérdidas que han soportado los productores. El levantamiento del EZLn se sumó al deterioro del campo y generó un ambiente altamente conflictivo que no permitió la inversión productiva. La conflictividad alcanzó a los grandes, medianos y pequeños productores, muchos perdieron su tierra y otros dejaron de invertir frente a la inseguridad. A poco más de una década del levantamiento armado, y a pesar de que el nivel de tensión ha bajado considerablemente, Chiapas vive una situación difícil en términos de economía agraria. 
En el escenario actual, los márgenes de organización y defensa de los derechos de los trabajadores migrantes son prácticamente nulos. Un mercado laboral segmentado y diferencial provoca, como señala Grammont (2001), un entrecruzamiento de itinerarios de trabajo que limita a los trabajadores para reconocerse entre sí, colocándolos en una situación de indefensión de sus derechos humanos más elementales. En los lugares de origen de los migrantes, la lucha agraria, las demandas de apoyos gubernamentales a la producción y los esfuerzos organizativos para derivar proyectos de autodesarrollo no han logrado detener el deterioro de las condiciones de vida de amplios sectores. En esta perspectiva, es de esperar una tendencia a la profundización de los flujos migratorios con destino a los estados del norte del país y a Estados Unidos. Las redes sociales y las facilidades de transporte, que han proliferado en los últimos años, hacen suponer que el fenómeno es ya irreversible y autorreproducible.

\section{BIBLIOGRAFÍA}

Alducin, Enrique (2005), «Dinámica de la emigración de México a Estados Unidos y monto de las remesas familiares», en Este País, núm. 177, diciembre, México.

Banco de México, Informes anuales, México.

Burke, Garance (2003), «Yucatecos y chiapanecos en San Francisco: la formación de comunidades de inmigrantes indígenas y su incorporación a un mercado laboral menguante», en Jonathan Fox y Gaspar Rivera-Salgado (coords.), Indígenas mexicanos migrantes en los Estados Unidos, México, Cámara de Diputados, Universidad Autónoma de Zacatecas, Grupo Editorial Miguel Ángel Porrúa.

Canales, Alejandro (2002), «Migración internacional y flexibilidad laboral en el contexto del TLCAN», en Revista Mexicana de Sociología, núm. 2, vol. LXII, abril-junio, México.

De Grammont, Hubert C. (2001), «El campo mexicano a finales del siglo XX», en Revista Mexicana de Sociología, núm. 4, octubre-diciembre, México, Instituto de Investigaciones Sociales, Universidad Nacional Autónoma de México.

Dírz-Canedo, Juan (1980), A New View of Mexican Migration to the U.S., Massachussets Institute of Technology (MIT).

Durand, Jorge y Massey S. Douglas (2003), Clandestinos. Migración México-Estados Unidos en los Albores del siglo XXI, México, Universidad Autónoma de Zacatecas, Grupo Editorial Miguel Ángel Porrúa.

Gobierno del Estado de Chiapas (2004), Propuesta de política migratoria para el Estado de Chiapas, Tuxtla Gutiérrez, Mimeo.

Inegi (2002), Chiapas. Perfil Sociodemográfico, Aguascalientes, XII Censo General de Población y Vivienda 2000. 
Censo General de Población y Vivienda 2000 (2001). Aguascalientes.

Encuesta Nacional de Empleo (2003), México.

INEGI, Anuario Estadístico de Chiapas, Gobierno del Estado de Chiapas.

Instituto Nacional de Migración, Centro de Estudios Migratorios (2005), Diagnóstico general de los flujos de trabajadores temporales en la frontera sur de México, México, Mimeo.

MAestries, Francis (2003), «Crisis cafetalera y migración internacional en Veracruz», en Migraciones Internacionales, vol. 2, núm. 2, julio-diciembre, México.

MAIER, Elizabeth (2003), "Migración y ciudadanía femenina indígena: cuerpos desplazados y la renegociación diaria del sujeto femenino», en Paloma Bonfil y Elvia Rosa Martínez (coords.), Diagnóstico de la discriminación hacia las mujeres indígenas, México, Comisión Nacional para el Desarrollo de los Pueblos Indígenas, Colección Mujeres Indígenas.

Mármora, Lelio (2002), Las politicas de migraciones internacionales, Buenos Aires, Paidós, Organización Internacional para las Migraciones.

Massey, Douglas S., Rafael Alarcón, Jorge Durand y Humberto González (1991), Los ausentes. El proceso social de la migración internacional en el occidente de México, México, conaculta, Alianza Editorial.

Migrantes (2004), revista de información y pastoral migratoria, núm. 2, julio-diciembre, Casa del Migrante Nazareth, Tijuana.

PapaIL, Jean y Jesús Arroyo (2004), Los dólares de la migración, México, Universidad de Guadalajara, Institut de Recherche pour le Développement.

Pimienta, Rodrigo y Marta Vera (2005), Dinámica migratoria interestatal en la República Mexicana, México, El Colegio Mexiquense.

PNUD (Programa de las Naciones Unidas para el Desarrollo) (2005), Informe sobre Desarrollo Humano México 2004, México, Mundi, Prensa México.

ReYes, María Eugenia (1994), Reparto de tierras en Chiapas, México, Universidad Nacional Autónoma de México, Centro de Investigaciones Humanísticas de Mesoamérica y Chiapas.

Rus, Diane y Jean Rus (2005), «Notas sobre la migración Chamula a los Estados Unidos», México, CIESAS, Mimeo.

Salazar, Pablo (2003), Tercer Informe de Gobierno. A la mitad de un buen camino, anexo estadístico, Tuxtla Gutiérrez.

Santibáñez, Jorge (2005), "El Banco de México y las remesas chiapanecas», en El Financiero, 30 de junio, p. 24.

SeCRETARÍA de Economía (2003), Subdirección de Inversión Extranjera, Inversión Extranjera Directa.

Villafuerte, Daniel (2001) «Chiapas: los espacios opacos de la globalización», en Pueblos y Fronteras, núm. 1, UNAM, IIA, Programa de Investigaciones Multidisciplinarias sobre Mesoamérica y el Sureste, México, pp. 147-165. (2003), "Chiapas: Las fronteras del desarrollo», en Liminar, revista de investigación del Centro de Estudios Superiores de México y Centroamérica, 
Universidad de Ciencias y Artes de Chiapas, año 1, núm. 1, junio, México, pp. 69-98.

Villafuerte, Daniel et al. (1999), Sistema de ciudades de Chiapas. Un enfoque socioeconómico y demográfico, Tuxtla Gutiérrez, Universidad de Ciencias y Artes de Chiapas.

(2002), La tierra en Chiapas. Viejos problemas nuevos, México, Fondo de Cultura Económica.

Villafuerte, Daniel, María del Carmen García y Salvador Meza (1997), La cuestión ganadera y la deforestación. Viejos y nuevos problemas en el trópico y Chiapas, Tuxtla Gutiérrez, Universidad de Ciencias y Artes de Chipas.

Wodon, Quentin, Gladis López y Corine Siaens (2004), Pobreza en los estados del sur de México, México, Grupo del Banco Mundial, Dirección Subregional para Colombia y México.

\section{HEMEROGRAFÍA}

Cuarto Poder, 12 de julio de 1997, Tuxtla Gutiérrez, Chiapas, México.

Cuarto Poder, 13 de abril de 2005, Tuxtla Gutiérrez, Chiapas, México.

Cuarto Poder, 14 de abril de 2005, Tuxtla Gutiérrez, Chiapas, México.

Cuarto Poder, 5 de octubre de 2004, Tuxtla Gutiérrez, Chiapas, México.

Cuarto Poder, 7 de enero de 1998, Tuxtla Gutiérrez, Chiapas, México.

Cuarto Poder, 9 de enero de 1998, Tuxtla Gutiérrez, Chiapas, México.

El Financiero, 10 de octubre de 2000, México.

El Financiero, 2 de abril de 2004, México.

El Financiero, 10 de octubre de 2005, México.

El Heraldo de Chiapas, 6 de septiembre de 2004, Tuxtla Gutiérrez, Chiapas, México.

El Heraldo de Chiapas, 20 de agosto de 2005, Tuxtla Gutiérrez, Chiapas, México.

La Jornada, 12 de octubre de 1992, México.

La Jornada, 15 de abril de 2001, México.

La Jornada, 25 de enero de 2005, México.

La Jornada, 19 de junio de 2005, México. 